washouts, but emphasised that this was to be discontinued as soon as automatic bladder function was established. But, at the same time as concerning himself with these practical essentials, he also saw the supreme importance of creating a "cheerful atmosphere," "impregnated with enthusiasm" and with "high morale."

Nevertheless, clinical exactitude alone would not have been enough to change the lot of paraplegics. A talent for organising and implementing was needed, and Guttman had it. He was a great advocate of what has since become the norm in managing many conditions, "a team approach." Not only are many different kinds of specialist doctors needed to manage paraplegics, but doctors, nurses, physiotherapists, and occupational therapists must all work closely together if success is to be achieved. He recognised the importance of games and work, inventing a game of "wheelchair polo," and organising work locally for his patients in hospital. Sir Ludwig could also get things done and cut through red tape, essential skills for founding a new discipline in postwar Britain. His vision and his organising skill combined to introduce international paraplegic games in 1952; an International Medical Society of Paraplegia in 1961; and a new journal, Paraplegia, in 1963.

His fourth talent, a talent to inspire, was also essential in his success. He inspired the paraplegics to recover, and by sheer weight of personality and presence he inspired nurses to turn patients as often as half-hourly all through the night. One of his patients of those times describes in the special issue of Paraplegia how Sir Ludwig "lived, talked, and must have dreamt paraplegia" and how he "bullied" his patients to recover.

At 80 Sir Ludwig retains the energy to continue with his crusade. He argues cogently that more beds are needed for the care of paraplegics and tetraplegics. There are many parts of the world, he recognises, some of them otherwise medically well endowed, where paraplegia is not well managed, and he has personally visited over 35 countries. He thinks, too, that the management of the spinally injured is a specialty on its own and should be recognised as such. Finally, Sir Ludwig argues that although the community has become more aware of its responsibility to the disabled there is still room for improvement.

\footnotetext{
1 Guttman, L, Paraplegia, 1979, 17, 6.
}

\section{Treatment of biliary atresia}

Until recently the outlook for children born with biliary atresia was dismal. A small proportion of cases-not more than $10^{\circ}{ }_{0}$-are surgically correctable ${ }^{1}$; in these there are patent proximal extrahepatic ducts, only the distal part being atretic, so that an anastomosis can be made to some part of the intestine. Most, however, have been considered "non-correctable," there being no patent extrahepatic biliary ducts and so no chance of anastomosis. Only about $1 \%$ of patients with uncorrected atresia survive, ${ }^{2}$ and even among those with correctable lesions operated on successfully threequarters suffer from progressive cirrhosis. ${ }^{3}$

In 1959 Kasai and Suzuki reported a new operation for "non-correctable" biliary atresia. ${ }^{4}$ They found that transection of the fibrous tissue at the porta hepatis resulted in a flow of bile, and so have been able to perform a successful drainage operation by anastomosing the bowel to the porta hepatis. For several reasons general acceptance of this approach was slow. Firstly, the procedure was not described in an English language journal until $1968^{5}$; secondly, there was a misconception that atresia of the extrahepatic bile ducts was accompanied by a similar intrahepatic atresia; and, lastly, an anastomosis between bowel and the raw surface of the liver went against the fundamental surgical principle that mucosa must be sutured to mucosa. ${ }^{6}$ In the last few years, however, large series of cases of portoenterostomy have been reported both from Japan ${ }^{7}$ (where biliary atresia seems to be much more common than in Western countries) and from other parts of the world. ${ }^{8}$ Surgeons have found that sustained drainage of bile and disappearance of jaundice can be achieved in around $30^{\circ}{ }_{0}$ of patients; most of the children have normal physical growth ${ }^{9}$; and some have survived for as long as 23 years. ${ }^{3}$ Cholangitis, however, is frequent in these patients, especially during the first year after operation, ${ }^{9}$ and continuing liver disease is common.

Nevertheless, the success of Kasai's operation has stimulated a new interest in biliary atresia, the progression of cirrhosis despite adequate drainage of bile having focused attention on the cause of the disorder and the pathophysiological changes. There has been ample opportunity for detailed histological studies. As long ago as 1901 Rolleston and Hayne ${ }^{10}$ suggested that biliary atresia might result from "descending cholangitis" rather than anomalous development; but not until 1974 did Landing ${ }^{11}$ suggest that neonatal hepatitis and biliary atresia could be two presentations of a single disease, which he named "infantile obstructive cholangiopathy." Haas ${ }^{12}$ studied liver biopsy specimens, portions of liver next to the porta hepatis resected at operation, and extrahepatic duct remnants from 17 patients operated on for the relief of biliary atresia, showing that inflammatory changes were present both in the entire duct system and in liver tissue. These changes in the ducts were similar to those found in the livers of some patients with severe viral hepatitis and associated with giant cell transformation, suggesting a common aetiology for the abnormalities of hepatocellular damage in neonatal hepatitis and of ductal drainage in biliary atresia. These changes may still be found in liver biopsy specimens after successful portoenterostomy.

Experience has improved the results, and $60^{\circ}$ o or more of the patients ${ }^{1314}$ are now claimed to survive after portoenterostomy, free of jaundice and with stable liver function. These excellent results depend on three factors: early surgery, good operative technique, and avoidance of postoperative cholangitis. The incidence of postoperative cholangitis has been reduced by various methods of venting the bilioenteric conduit and by using choleretic agents and prophylactic antibiotics. ${ }^{15}$ Rickham and Hirsig ${ }^{16}$ have proposed (on experimental evidence) that postoperative cholangitis is due not to ascending infection but to interference with the lymphatic drainage from the porta hepatis during the operation; by performing an omentopexy to a raw area of liver near the porta hepatis they have eliminated postoperative cholangitis both in pigs and in patients-though they have only a few cases, followed up for at most two and a half years. Operative technique is important, since the fibrous cord at the porta hepatis needs to be divided at a level where there are patent ductules of adequate size; if the transection is too superficial the ducts may still be obliterated, and if too deep it may be beyond the larger ducts-biliary ductules with a diameter of less than $150 \mu$ offer no hope of success. Kasai ${ }^{13}$ has made detailed anatomical studies and has recently described a 
critical point of dissection, directly above the bifurcation of the portal vein and as far posteriorly as its posterior wall. Suruga has attributed improved results to the use of an operating microscope. ${ }^{17}$

Early surgery is of prime importance. Progressive cirrhosis will certainly be established by the age of 3 months and probably sooner. Sixty days is now regarded as the maximum age at which portoenterostomy can be carried out with any hope of arresting the disease, even if adequate bile drainage is achieved. Hence time is limited. In the newborn child with persistent jaundice the main problem is distinguishing between neonatal hepatitis and biliary atresia. A battery of tests is available to differentiate between hepatocellular disease and ductal obstruction, but since the conditions overlap these cannot provide an unequivocal diagnosis. This requires liver biopsy and an operative cholangiogram-a simple procedure that should be carried out at the beginning of the investigations and not at the end. If the clinician yields to the temptation of embarking on new and exotic liver function tests he may delay surgical treatment and so allow the onset of irreversible, progressive cirrhosis.

${ }^{1}$ Ladd, W E, fournal of the American Medical Association, 1928, 91, 1082.

2 Adelman, S J, fournal of Pediatric Surgery, 1978, 13, 389.

3 Kasai, M, Progress in Pediatric Surgery, 1974, 6, 5.

Kasai, M, and Suzuki, S, Shujutsu, 1959, 13, 733.

5 Kasai, M, et al, fournal of Pediatric Surgery, 1968, 3, 665.

${ }^{6}$ Danks, D M, and Smith, A L, World Fournal of Surgery, 1978, 2, 585.

${ }^{7}$ Kasai, M, Watanabe, I, and Ohi, R, Fournal of Pediatric Surgery, 1975 , 10, 173 .

${ }^{8}$ Lilly, J R, Annals of Surgery, 1977, 186, 549.

9 Odièvre, M, World fournal of Surgerv, 1978, 2, 589

10 Rolleston, H D, and Hayne, L B, British Medical fournal, 1901, 1, 758.

${ }^{11}$ Landing, B H, Progress in Pediatric Surgery, 1974, 6, 113.

${ }^{12}$ Haas, J E, World Fournal of Surgery, 1978, 2, 561.

$13 \mathrm{Kasai}, \mathrm{M}$, et al, World Fournal of Surgery, 1978, 2, 571.

14 Suruga, K, World fournal of Surgery, 1978, 2, 593.

${ }^{15}$ Lilly, J R, and Hitch, D C, World fournal of Surgery, 1978, 2, 581.

${ }^{16}$ Rickham, P P, and Hirsig, J, Zeitschrift für Kinderchirurgie und Grenzgebiete, $1978,26,114$.

17 Suruga, K, et al, Surgery, 1976, 80, 558.

\section{Dissolution of renal stones}

The treatment of patients with urinary stones has two aspects: firstly, dissolving or surgically removing stones already lodged in the urinary tract; and, secondly, preventing recurrence. Generally, recurrence of most types of stone should now be preventable with dietary and medical measures. Dissolution of existing stones, however, is much more difficult, since the urine has to be made undersaturated with the salt or acid concerned continuously for several days or even weeks. This is feasible in the case of cystine, uric acid, magnesium ammonium phosphate, and even calcium phosphate stones; but it is extremely difficult with calcium oxalate stones, ${ }^{1}$ which are the most common of all urinary calculi.

The main alternative to dissolving the stone is surgical removal. This may be necessary if there is ureteric or intrarenal obstruction. With most types of operation, however, there is a high risk of recurring stones. ${ }^{2+}$ The exception appears to be partial nephrectomy, usually of the lower pole, ${ }^{56}$ but the operation has been criticised as being unsuitable for most renal stones because renal tissue is lost without any proved benefit to the patient. ${ }^{7}$ Furthermore, all surgical operations carry a risk of introducing infection. ${ }^{8}$
Among some more exotic methods reported in recent years for eliminating stones from the urinary tract are mechanical vibration of the patient, ${ }^{9}$ ultrasonic lithotripsy (first reported in $\operatorname{dogs}^{1011}$ but later in patients ${ }^{12}$ ), and ureteral ${ }^{13-16}$ and intrarenal irrigation. ${ }^{17-20}$ In the irrigation procedures solutions (based on citric acid or ethylene diamine tetra-acetic acid or both) able to render calcium and magnesium salts soluble are perfused through the urinary system. The techniques used so far include retrograde catheterisation, ${ }^{13-16}$ insertion of a nephrostomy tube after pyelolithotomy, ${ }^{17-19}$ and percutaneous nephrostomy. ${ }^{20}$ By these procedures phosphatic, ${ }^{13-20}$ cystine, ${ }^{21}$ and uric acid stones ${ }^{22}$ can be dissolved-calcium oxalate stones remaining the most refractory. Some of the advantages claimed for the technique are the direct contact between the solvent and the stone, the minimal dilution of the solvent during the normal course of urine production, and the relative ease with which the kidney may be irrigated by nephrostomy.

Despite reported successes, however, irrigation is not widely used. The main reasons seem to be that treatment has to be continued for between one and four weeks; adequate lavage often proves difficult to provide and maintain; blockage of the catheters by fragments of stone may be a problem; and, finally, surgical nephrostomy requires the same general anaesthesia and exposure of the kidney as pyelolithotomy or nephrolithotomy, and therefore offers no real advantage over surgical removal of the stone. Complications arising from irrigation include infection of the urinary tract, ${ }^{16}$ local intolerance of the irrigating fluid, ${ }^{23}{ }^{24}$ tissue damage leading to renal failure, ${ }^{25}$ and hypermagnesaemia. ${ }^{26}$

More recently, percutaneous nephrostomy has been developed to allow catheters large enough for adequate irrigation and drainage to be introduced directly into the renal collecting system. ${ }^{20}$ This removes the need for open surgery and general anaesthesia and avoids the problems of ureteral catheterisation. Urologists using this technique, however, have been at pains to point out that it should complement surgical removal rather than compete with it. Percutaneous nephrostomy is most appropriate for patients unfit for surgery and those who have previously undergone multiple renal operations. The scope of the technique, however, will be severely limited so long as the available irrigation fluids do not dissolve calcium oxalate. Preparations containing salts of ethylene diamine tetra-acetic acid are said to be more effective for this, ${ }^{21}$ but they may cause severe pain. ${ }^{16}$ Until these problems are overcome irrigation techniques for dissolving stones are unlikely to supersede more conservative forms of treatment.

${ }^{1}$ Robertson, W G, and Nordin, B E C, in Scientific Foundations of Urology, vol 1, ed D I Williams and G D Chisholm, p 254. London, Heinemann, 1976.

- Sutherland, J W, British fournal of Urology, 1954, 26, 22

${ }^{3}$ Williams, R E, British fournal of Urology, 1963, 35, 416.

4 Williams, R E, British Fournal of Urology, 1972, 44, 292.

"Stewart, H H, British fournal of Urology, 1960, 32, 392.

${ }^{6}$ Rose, M B, and Follows, O J, British Fournal of Urology, 1977, 49, 605.

Marshall, V R, et al, British Fournal of Urology, 1975, 47, 759.

${ }^{8}$ Cox, C E, Urologic Clinics of North America, 1974, 1, 279.

${ }^{9}$ Cottet, J, Wisner, A, and Berthoz, A, Bulletin de l'Académie Nationale de Médecine, 1968, 152, 111.

${ }^{10}$ Howards, S S, et al, Investigative Urology, 1974, 11, 273.

${ }^{11}$ Eisenberger, F, et al, Fortschritte der Urologie und Nephrologie, 1977, 9, 387.

12. New Scientist, 1978, 79, 326.

${ }^{13}$ Mulvaney, W P, fournal of Urology, 1960, 84, 206.

${ }^{14}$ Davis, T A, Fournal of Urology, 1964, 92, 599.

${ }_{15}$ Timmermann, A, and Kallistratos, G, Fournal of Urology, 1966, 95, 469.

${ }^{16}$ Mischol, H R, and Wildbolz, E, Fournal of Urologv, 1971, 105, 607.

17 Nemoy, N J, and Stamey, T A, fournal of the American Medical Association, 1971, 215, 1470.

18 Weiser, M, Acta Urologica Belgica, 1971, 39, 328. 